\title{
Mesoporous MEL, BEA, and FAU zeolite crystals obtained by in situ formation of carbon template over metal nanoparticles
}

Abildstrøm, Jacob Oskar; Ali, Zahra Nasrudin; Mentzel, Uffe Vie; Mielby, Jerrik Jørgen; Kegnæs, Søren; Kegnæs, Marina

Published in:

New Journal of Chemistry

Link to article, DOI:

10.1039/c5nj02809d

Publication date:

2016

Document Version

Peer reviewed version

Link back to DTU Orbit

Citation $(A P A)$ :

Abildstrøm, J. O., Ali, Z. N., Mentzel, U. V., Mielby, J. J., Kegnæs, S., \& Kegnæs, M. (2016). Mesoporous MEL, BEA, and FAU zeolite crystals obtained by in situ formation of carbon template over metal nanoparticles. New Journal of Chemistry, 40(5), 4223-4227. https://doi.org/10.1039/c5nj02809d

\section{General rights}

Copyright and moral rights for the publications made accessible in the public portal are retained by the authors and/or other copyright owners and it is a condition of accessing publications that users recognise and abide by the legal requirements associated with these rights.

- Users may download and print one copy of any publication from the public portal for the purpose of private study or research.

- You may not further distribute the material or use it for any profit-making activity or commercial gain

- You may freely distribute the URL identifying the publication in the public portal 


\title{
Journal Name
}

\section{ARTICLE}

\section{Mesoporous MEL, BEA, and FAU zeolite crystals obtained by in- situ formation of carbon template over metal nanoparticles}

Received 00th January 20xx, Accepted 00th January 20xx

DOI: $10.1039 / x 0 x \times 00000 x$

www.rsc.org/

\author{
Jacob Oskar Abildstrøm, ${ }^{a}$ Zahra Nasrudin Ali, ${ }^{a}$ Uffe Vie Mentzel, ${ }^{b}$ Jerrik Mielby, ${ }^{a}$ Søren Kegnæs ${ }^{a, *}$ \\ and Marina Kegnæs ${ }^{\text {, }}$
}

\begin{abstract}
Here, we report the synthesis and characterization of hierarchical zeolite materials with MEL, BEA and FAU structures. The synthesis is based on the carbon templating method with an in-situ-generated carbon template. Through the decomposition of methane and deposition of coke over nickel nanoparticles supported on silica, a carbon-silica composite is obtained and exploited as a combined carbon template/silica source for the zeolite synthesis. The mesoporous zeolite materials were all prepared by hydrothermal crystallization in alkaline media followed by removal of the carbon template by combustion, which results in zeolite single crystals with intracrystalline pore volumes of up to $0.44 \mathrm{~cm}^{3} / \mathrm{g}$. The prepared zeolite structures are characterized by XRD, SEM, TEM and $\mathrm{N}_{2}$ physisorption measurements.
\end{abstract}

\section{Introduction}

Zeolites are crystalline inorganic materials with an ordered microporous structure and strong acid sites that are extensively used as heterogeneous catalysts in oil refining and chemical synthesis [1, 2]. Furthermore, zeolites possess high surface areas and large pore volumes and are therefore used in many modern industrial processes related to catalysis, adsorption, and separation, where they provide excellent sizeand shape-selectivity [3, 4]. However, the large-scale application of zeolites has still not reached its full potential [5], because zeolite catalysts often suffer from severe diffusion limitations. Since the reactants and products have to diffuse through the micropores in order to reach and leave the active sites, the diffusion in zeolites is often orders of magnitude slower than both molecular and Knudsen diffusion. These diffusion limitations are enhanced for large and bulky compounds that closely match the pore sizes of the zeolites and will inevitably slow down the reaction rate.

Moreover, in some reactions, coke formation enhances these limitations, as the coke deposits block the zeolite micropores, which results in a rapid decrease in catalytic activity $[6,7]$. Therefore, several preparative strategies have been developed in the attempt to improve the performance of zeolites in catalysis: the synthesis of zeolites with extra-large pores [8 11], direct synthesis of zeolite nanocrystals [12-17], by exfoliating layered zeolites [18, 19], and by introducing mesopores in the microporous materials through templating

\footnotetext{
${ }^{a .}$ Department of Chemistry, Technical University of Denmark, DK-2800 Kgs. Lyngby, Denmark.Email:skk@kemi.dtu.dk

${ }^{b}$ Haldor Topsøe A/S, Haldor Topsøes Allé 1, DK-2800 Kgs. Lyngby, Denmark

Electronic Supplementary Information (ESI) available: Physisorption analysis and xrpd of conventional materials. See DOI: 10.1039/x0xx00000x
}

strategies [7, 20 - 22] or demetallation processes [4, 7, 23-25]. Recently, a novel synthesis procedure for the preparation of mesoporous MFI-type material based on the carbon templating method with an in-situ-generated carbon template was reported by our group [26]. The mesoporous zeolite crystals combine the shape-selectivity, hydrothermal stability, and high acidity typical for conventional zeolites with highly efficient transport of reactants and products typical for mesoporous materials [7]. The novel synthesis approach has several advantages in comparison with existing carbon templating methods, where relatively complicated preparative strategies involving multistep impregnation procedures are used [27-30]. In the presented approach a cheap and available silica source - silica gel $\left(\mathrm{SiO}_{2}\right)$ is used. The carbon template is generated in situ by decomposition of methane, which results in the formation of large amounts of coke around the silica supported nickel nanoparticles [26]. The formation of coke over metal nanoparticles is a well-known phenomenon for a range of catalytic reactions that is frequently investigated [31]. For the decomposition of methane, supported nickel nanoparticles are recognized as effective catalysts [32]. In this way, the novel synthesis approach is more cost effective in comparison with the conventional carbon templating approach that relies on relatively expensive starting materials such as carbon black pearls and tetraethyl orthosilicate $[7,27,28,30]$. The encapsulated carbon is removed by combustion after the zeolite crystallization, which creates mesoporosity in the zeolite crystals. In Fig. 1 a schematic overview of the presented synthesis approach is given. 


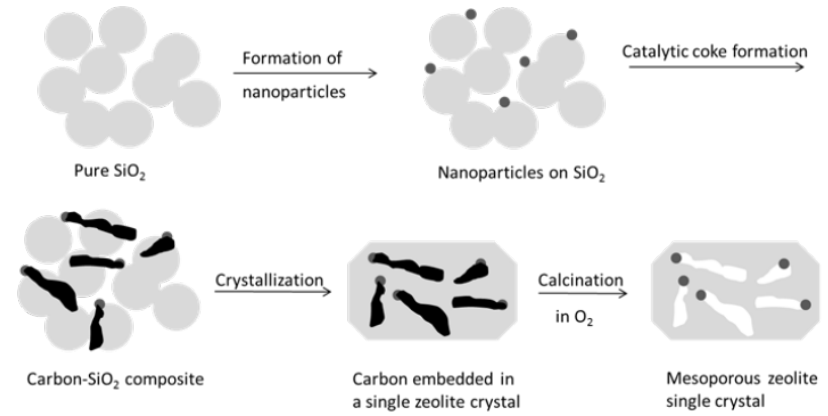

Fig. 1. Synthesis scheme for preparation of mesoporous zeolite single crystals based on the carbon templating method with an in-situ-generated carbon template.

Furthermore, this novel synthesis method allows preparation of mesoporous zeolites with desirable acidity, which is challenging in the case of the conventional carbon templating method [33].

Here, we report the recent progress on the synthesis and characterization of mesoporous zeolites with MEL, BEA and FAU structures using an in-situ-generated carbon template obtained by decomposition of methane over nickel nanoparticles. The results demonstrate that our synthetic strategy is general and opens up for simple and cost-effective synthesis of several important industrial zeolite catalysts in mesoporous form.

\section{Experimental}

\subsection{X-ray Powder Diffraction}

$X$-ray powder diffraction patterns were recorded in transmission mode using $\mathrm{Cu}-\mathrm{K} \alpha$ radiation from a focusing quartz monochromator and a Huber G760 Guinier camera in the $2 \theta$ interval $5-60^{\circ}$.

\subsection{Nitrogen Physisorption}

Nitrogen adsorption and desorption measurements were performed at liquid nitrogen temperature on a Micromeritics ASAP 2020. The samples were outgassed in vacuum at $200^{\circ} \mathrm{C}$ during $18 \mathrm{~h}$ prior to measurement. Total surface area was calculated according to the BET method. Total- and micropore volumes were determined by the BJH method (desorption branch) and $t$-plot method respectively.

\subsection{Scanning Electron Microscopy}

Scanning electron microscopy (SEM) was performed on Quanta 200 ESEM FEG operated at $10 \mathrm{kV}$, with the calcined zeolite samples placed on a carbon film and $\mathrm{Au}$ was evaporated onto the samples for 5 seconds to achieve the sufficient conductivity.

\subsection{Transmission Electron Microscopy}

Transmission electron microscopy (TEM) was performed on a FEI Tecnai microscope operated at $200 \mathrm{kV}$ with the samples dispersed directly on holey carbon grids.

\subsection{Materials}

All reagents were of reagent grade and used without further purifications: tetrabutylammonium hydroxide (TBAOH, 40 wt\%, Sigma-Aldrich), tetraethylammonium hydroxide (TEAOH, 35 wt\%, Sigma-Aldrich), silica gel $\left(\mathrm{SiO}_{2}\right.$, Davisil Grade 62, pore size $150 \AA$ A 60-200 mesh, Sigma-Aldrich), sodium hydroxide $(\mathrm{NaOH}, 97 \%, \mathrm{VWR})$, sodium aluminate $\left(\mathrm{NaAlO}_{2}, 54\right.$ wt \% $\mathrm{Al}_{2} \mathrm{O}_{3}$ and 41 wt \% $\mathrm{Na}_{2} \mathrm{O}$, Riedel-de Haen), aluminium nitrate $\left(\mathrm{Al}\left(\mathrm{NO}_{3}\right)_{3} \cdot 9 \mathrm{H}_{2} \mathrm{O}\right.$, Riedel-de Haen), nickel nitrate hexahydrate $\left(\mathrm{Ni}\left(\mathrm{NO}_{3}\right)_{2} \cdot 6 \mathrm{H}_{2} \mathrm{O}\right.$, Sigma-Aldrich), methane gas $\left(\mathrm{CH}_{4}, \mathrm{AGA}\right)$, forming gas $\left(10 \% \mathrm{H}_{2} / \mathrm{N}_{2}, A G A\right)$, argon gas ( $\left.\mathrm{Ar}, \mathrm{AGA}\right)$ and distilled water.

\subsection{Zeolite Synthesis}

\subsubsection{Preparation of Ni-containing silica-carbon composite} material. The silica-carbon composite was prepared by the following procedure. $0.15 \mathrm{~g}$ of $\mathrm{Ni}\left(\mathrm{NO}_{3}\right)_{2} \cdot 6 \mathrm{H}_{2} \mathrm{O}$ was dissolved in $1.73 \mathrm{~g}$ of water. $1.50 \mathrm{~g}$ of $\mathrm{SiO}_{2}$ was impregnated with this solution to incipient wetness. The resulting material was dried overnight at room temperature and then reduced in a flow of $10 \% \mathrm{H}_{2} / \mathrm{N}_{2}$ (with a ramp of $20^{\circ} \mathrm{C} / \mathrm{min}$ ) at $600{ }^{\circ} \mathrm{C}$ for 4 hours, followed by calcination in a flow of Ar until temperature was fallen to $550{ }^{\circ} \mathrm{C}$. Then the obtained materials were subjected to $\mathrm{CH}_{4}$ flow at $550{ }^{\circ} \mathrm{C}$ for 8 hours.

2.6.2 Synthesis of Ni-containing mesoporous MEL-type zeolite. The mesoporous $\mathrm{Ni}$-containing $\mathrm{Na}-\mathrm{ZSM}-11$ material was prepared according to the following procedure. In a 100 $\mathrm{ml}$ flask, $3.16 \mathrm{~g}$ of $\mathrm{H}_{2} \mathrm{O}, 0.14 \mathrm{~g}$ of $\mathrm{NaOH}$ and $0.21 \mathrm{~g}$ of $\mathrm{Al}\left(\mathrm{NO}_{3}\right)_{3} \cdot 9 \mathrm{H}_{2} \mathrm{O}$ were added with stirring and mixed with the $\mathrm{Ni}-$ containing silica-carbon composite obtained above (2.6.1). Then, $3.18 \mathrm{~g}$ of TBAOH was added to this mixture. The composition of the resulting synthesis gel was $1 \mathrm{Al}_{2} \mathrm{O}_{3}: 91 \mathrm{SiO}_{2}$ : 9.1TBA $\mathrm{TB}_{2} \mathrm{O}: 6.5 \mathrm{Na}_{2} \mathrm{O}: 1055 \mathrm{H}_{2} \mathrm{O}$. The final composite material was placed in a Teflon beaker inside a stainless steel autoclave, containing $15 \mathrm{~g}$ of water to produce saturated steam, heated to $175{ }^{\circ} \mathrm{C}$ and kept there for $24 \mathrm{~h}$. Then, the autoclave was cooled to room temperature, the product was washed with deionized water $(1 \mathrm{l})$ and filtered by suction. Finally, the product was dried at $90{ }^{\circ} \mathrm{C}$ for $10 \mathrm{~h}$, and the organic template and the carbon were removed by controlled combustion in air in a muffle furnace at $550{ }^{\circ} \mathrm{C}$ for $24 \mathrm{~h}$.

2.6.3. Synthesis of Ni-containing mesoporous BEA-type zeolite. The mesoporous $\mathrm{Ni}$-containing $\mathrm{Na}$-Beta material was prepared according to the following procedure. In a $100 \mathrm{ml}$ flask, $0.08 \mathrm{~g}$ of $\mathrm{NaOH}, 1.74 \mathrm{~g}$ of $\mathrm{H}_{2} \mathrm{O}, 0.17 \mathrm{~g}$ of $\mathrm{NaAlO}_{2}$ and 4.25 $\mathrm{g}$ of TEAOH were added with stirring until a clear solution was obtained. After that, the Ni-containing silica-carbon composite obtained above (2.6.1) was impregnated with this mixture. The composition of the resulting synthesis gel was $1 \mathrm{Al}_{2} \mathrm{O}_{3}: 28 \mathrm{SiO}_{2}$ : $5.6 \mathrm{TBA}_{2} \mathrm{O}: 2.4 \mathrm{Na}_{2} \mathrm{O}: 278 \mathrm{H}_{2} \mathrm{O}$. The final composite material was introduced into a stainless steel autoclave, containing $15 \mathrm{~g}$ of water to produce saturated steam, heated to $140^{\circ} \mathrm{C}$ and kept there for $144 \mathrm{~h}$. Then, the autoclave was cooled to room temperature, the product was washed with deionized water (1 
I) and filtered by suction. The zeolite was dried at $90^{\circ} \mathrm{C}$ for 10 $\mathrm{h}$, and the organic template and the carbon were removed by controlled combustion in air in a muffle furnace at $550{ }^{\circ} \mathrm{C}$ for $24 \mathrm{~h}$.

2.6.4. Synthesis of Ni-containing mesoporous FAU-type zeolite. The synthesis of mesoporous FAU-type crystals was based on the recipe from the patent by Christensen et al. Example 9 [34]. In a typical synthesis procedure, the freshly prepared chemicals were used: sodium silicate $\left(200 \mathrm{~g} / \mathrm{S} \mathrm{SiO}_{2}\right)$, sodium aluminate solution $\left(240 \mathrm{~g} / \mathrm{Al}_{2} \mathrm{O}_{3}\right.$ ), sodium hydroxide solution (400 $\mathrm{g} \mathrm{Na}_{2} \mathrm{O} / \mathrm{l}$ ). The mesoporous $\mathrm{NaY}$ material was prepared using seed gel according to the following procedure. Seed gel was made by the followed recipe: in $100 \mathrm{ml}$ flask 9.3 $\mathrm{ml}$ of sodium aluminate solution $\left(240 \mathrm{~g} / \mathrm{l} \mathrm{Al}_{2} \mathrm{O}_{3}\right), 19.97 \mathrm{ml}$ of sodium hydroxide solution $\left(400 \mathrm{~g} / \mathrm{I} \mathrm{Na}_{2} \mathrm{O}\right)$ and $50 \mathrm{ml}$ of sodium silicate $\left(200 \mathrm{~g} / \mathrm{I} \mathrm{SiO}_{2}\right)$ were added slowly with stirring. After that the mixture was left for 4 hours. Synthesis gel was prepared by the followed procedure: in $100 \mathrm{ml}$ flask $4.4 \mathrm{ml}$ of sodium aluminate solution $\left(240 \mathrm{~g} / \mathrm{I} \mathrm{Al}_{2} \mathrm{O}_{3}\right), 2.35 \mathrm{ml}$ of sodium hydroxide solution $\left(400 \mathrm{~g} / \mathrm{l} \mathrm{Na}_{2} \mathrm{O}\right.$ ) and $5.46 \mathrm{ml}$ of sodium silicate $\left(200 \mathrm{~g} / \mathrm{S} \mathrm{SiO}_{2}\right)$ were added slowly with stirring. After that, the $\mathrm{Ni}$-containing silica-carbon composite obtained above (2.6.1) and $0.48 \mathrm{ml}$ of seed gel was added slowly. The mixture was left for 1 hour with stirring. The composition of the resulting synthesis gel was $1 \mathrm{Al}_{2} \mathrm{O}_{3}: 7 \mathrm{SiO}_{2}$ : $5 \mathrm{Na}_{2} \mathrm{O}: 85 \mathrm{H}_{2} \mathrm{O}$. Then the gel was introduced into a stainless steel autoclave, containing $15 \mathrm{~g}$ of water to produce saturated steam, heated to $100^{\circ} \mathrm{C}$ and kept there for $18 \mathrm{~h}$. Then, the autoclave was cooled to room temperature, the product was washed with deionized water (1L) and filtered by suction. The zeolite was dried at $90^{\circ} \mathrm{C}$ for $10 \mathrm{~h}$, and the carbon template was removed by controlled combustion in air in a muffle furnace at $550^{\circ} \mathrm{C}$ for $24 \mathrm{~h}$.

2.6.5. Synthesis of reference conventional zeolite materials. All conventional materials MEL, BEA and FAU were synthesized the same way as the corresponding mesoporous materials using $1.5 \mathrm{~g}$ of pure $\mathrm{SiO}_{2}$ instead of the Ni-containing silicacarbon composite described above (2.6.1).

\section{Results and Discussion}

All X-ray powder diffraction (XRPD) patterns were obtained after the zeolite synthesis and subsequent combustion of the organic template and/or the carbon material. XRPD patterns for the conventional- and mesoporous ZSM-11, Beta and Zeolite $Y$ zeolites are shown in Fig. 2. Based on these data, all obtained zeolites are concluded to be highly crystalline structured materials.

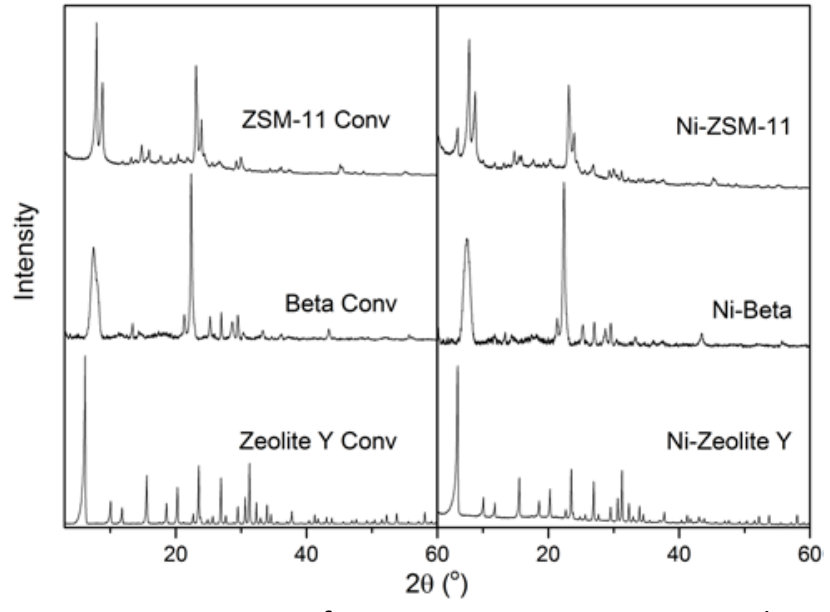

Fig. 2. XPRD patterns of mesoporous ZSM-11, Beta, and Zeolite Y-type materials.

In Fig. 3, the nitrogen adsorption and desorption isotherm of the conventional- and mesoporous ZSM-11, Beta and Zeolite $Y$ materials after combustion of the organic template and/or carbon are shown. In Table 1, the BET surface areas and pore volumes of the obtained ZSM-11, Beta and Zeolite $Y$ samples are summarized. According to the IUPAC classification of physisorption isotherms [35], all prepared mesoporous zeolites have Type IV isotherms. The isotherms contains a hysteresis loop at relative pressures higher than $p / p_{0}=0.4$, which is indicative for mesoporosity. Moreover, the hysteresis loop has an upward curvature at relative pressures above 0.8 . This upward curvature indicates the presence of cylindrical mesopores which are connected to the external surface area [35]. The pore size distribution of the prepared materials, are presented in the supplementary materials. It is apparent from Fig. 3 and Table 1 that mesoporous ZSM-11 and Beta zeolite samples obtained by novel method using in-situ-generated carbon template have standard pore volumes and are characterized by large surface areas [28, 30]. However, mesoporous Zeolite $Y$ sample has a rather moderate degree of 


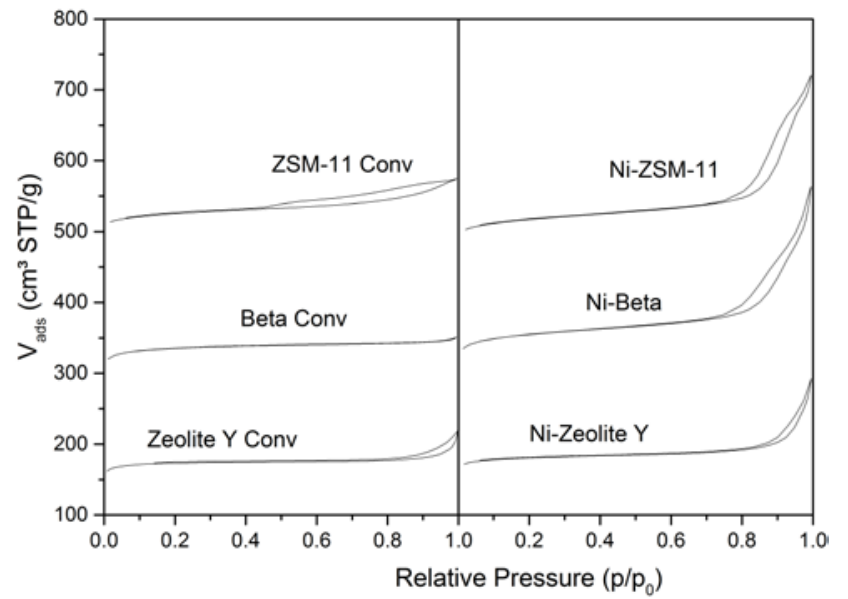

Fig. 3. Nitrogen adsorption and desorption isotherms of the mesoporous Ni-containing ZSM-11, Beta and Zeolite Y-type materials.

Table 1. Nitrogen physisorption and elemental analysis data.

\begin{tabular}{lccccc}
\hline Zeolite & $\begin{array}{c}\text { Conv/ } \\
\text { Meso }\end{array}$ & $\begin{array}{c}\mathrm{V}_{\text {micro }}{ }^{\mathrm{a}} \\
\left(\mathrm{cm}^{3} / \mathrm{g}\right)\end{array}$ & $\begin{array}{c}\mathrm{V}_{\text {total }}{ }^{\mathrm{b}} \\
\left(\mathrm{cm}^{3} / \mathrm{g}\right)\end{array}$ & $\begin{array}{c}\mathrm{S}_{\mathrm{BET}}{ }^{\mathrm{c}} \\
\left(\mathrm{m}^{2} / \mathrm{g}\right)\end{array}$ & $\begin{array}{c}\mathrm{Si} / \mathrm{Al} \\
\text { ratio }^{\mathrm{d}}\end{array}$ \\
\hline Ni-ZSM-11 & meso & 0.13 & 0.41 & 397 & 88 \\
ZSM-11 & conv & 0.14 & 0.22 & 409 & 88 \\
Ni-Beta & meso & 0.18 & 0.44 & 522 & 24 \\
Beta & conv & 0.22 & 0.27 & 553 & 22 \\
Ni-Zeolite Y & meso & 0.32 & 0.34 & 853 & 4.4 \\
Zeolite Y & conv & 0.33 & 0.35 & 886 & 4.6 \\
\hline
\end{tabular}

${ }^{\mathrm{a}}$ Calculated by $t$-plot method; ${ }^{\mathrm{b}}$ Calculated by BJH method; ${ }^{\mathrm{c} C a l c u l a t e d}$ by BET method; ${ }^{\mathrm{d}}$ Determined by ICP

mesoporosity [34] and as it is shown in our previous work [26], it can be improved by varying process parameters in 2.6.1. The different and a quite moderate degree of mesoporosity in Zeolite $Y$ compared to ZSM-11 and Beta could be due to the much different procedure for the preparation of the synthesis gel. As synthesized, Zeolite $Y$ has poor thermal/hydrothermal stability due to the high content of $\mathrm{Al}$ and $\mathrm{Na}$ in the structure. Therefore, the parent zeolite $Y$ is subjected to a series of modifications (stabilization) such as ion exchange followed by steam calcination to impart both acidity and stability into the structure. These modifications of zeolite $Y$ are relatively complicated, since the framework of zeolite $Y$ has to be partially destroyed in order to remove large amounts of $\mathrm{Na}$ and Al. Therefore, the introduction of even moderate degree of mesoporosity during the synthesis could improve the ability for the ion exchange of Zeolite $Y$ and thus lead to an improved and more stable ion exchange process on industrial scale. Moreover, it is seen from Table 1 that by using the presented synthesis method it is possible easily to obtain mesoporous zeolite crystals with desirable acidity (matching the acidity of conventional materials), which is challenging in the case of the conventional carbon templating method [33].
Representative results of SEM for the conventional and mesoporous ZSM-11, Beta and Zeolite $Y$ zeolites after combustion of the carbon template are shown in Fig. 4. From the SEM images it can be seen that all samples are highly crystalline and that crystals of uniform size are obtained. The average crystal size of both conventional and mesoporous zeolites determined from SEM images in Fig. 4 and are about 3 $\mu \mathrm{m}$ for ZSM-11, $1 \mu \mathrm{m}$ for Beta and $0.5 \mu \mathrm{m}$ for Zeolite Y.

The major difference between the conventional and mesoporous ZSM-11 and Beta zeolite crystals, is the presence of non-crystallographic intracrystalline mesopores resulting in the high porosity. The conventional zeolite ZSM-11 has the typical coffin-shape intergrown crystals, and the conventional Beta material has the typical rounded-cube shape. From the SEM images of the mesoporous ZSM-11 and Beta zeolites, it can be seen that the crystals have shapes typical for the mesoporous single crystals. The conventional and mesoporous crystals of Zeolite $Y$ materials look very similar due to rather moderate degree of mesoporosity in the mesoporous sample.

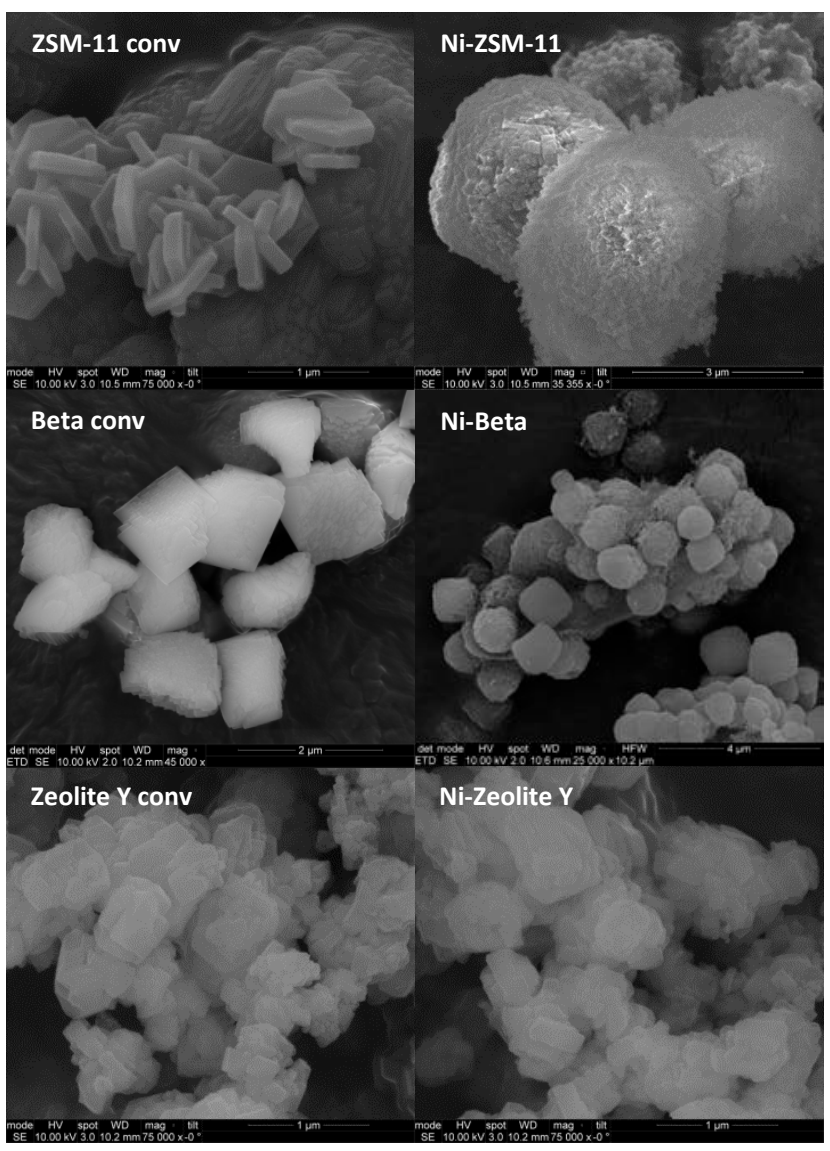

Fig. 4. SEM images of conventional and mesoporous ZSM-11, Beta and Zeolite Y-type materials. 


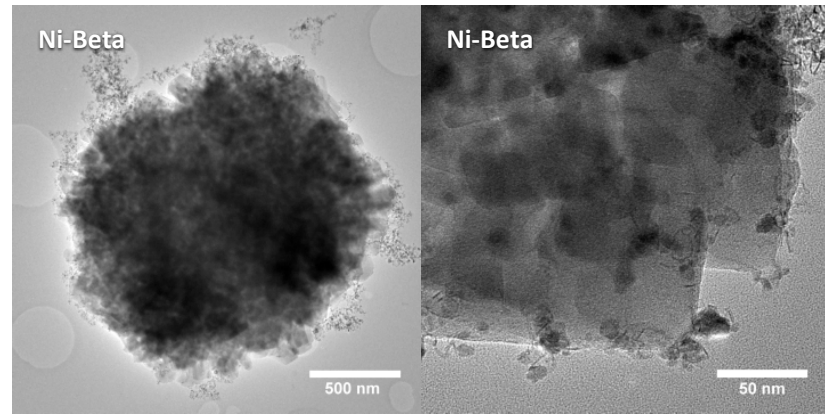

Fig. 5. TEM images of mesoporous Beta-type materials.

The results of transmission electron microscopy for the mesoporous Beta-type zeolites after combustion of the carbon are shown in Fig. 5 . It is easily possible to see the mesoporous zeolite crystal, which clearly features some brighter areas distributed all over. These brighter areas are the mesopores created by removal of the carbon. The sponge-like appearance of the crystal is typical for this kind of mesoporous single crystal materials obtained by using excess of a zeolite gel as described in details by Jacobsen et al. [27]. The nickel particles incorporated into the zeolite catalyst have an average particle size of $6 \mathrm{~nm}$ as it is determined from TEM images. It was shown previously $[30,36]$, that using the standard carbon templating synthesis procedure in alkaline media it is possible to get only nanosized Beta material. Here, we show that the use of novel synthesis procedure based on the carbon templating method with an in-situ-generated carbon template allowed us to obtain mesoporous zeolite Beta single crystal materials. TEM images of the mesoporous Ni-ZSM-11 zeolite are presented in the supplementary material.

\section{Conclusions}

In conclusion, the preparation of mesoporous ZSM-11, Beta and Y-type zeolite single crystals modified with $\mathrm{Ni}$ nanoparticles based on the carbon templating method with an in-situ-generated carbon template is reported for the first time. The obtained zeolite materials combine high crystallinity with an intracrystalline mesopore system with pore volume of up to $0.44 \mathrm{~cm}^{3} / \mathrm{g}$. Compared to existing carbon templating procedures, this method does not rely on the availability of special and expensive chemicals, only on the mesoporous silica that are used widely and can be obtained easily by precipitation. Moreover, we show that the use of novel synthesis procedure based on the carbon templating method with an in-situ-generated carbon template allowed us to obtain mesoporous zeolite Beta in alkaline media.

Thus, with this novel and simple preparation method, it will be possible that mesoporous zeolites with incorporated nickel nanoparticles could find use in industrial applications.

\section{Acknowledgements}

The authors gratefully acknowledge the support of the Danish Council for Independent Research, Grant No. 2-127580 and the support of the Lundbeck Foundation (Lundbeckfonden), Grant No. R141-2013-13244.

\section{Notes and references}

1 A. Corma, Chem. Rev., 1995, 95, 559.

2 C. Martínez, A. Corma, Coord. Chem. Rev., 2011, 255, 1558.

3 J. Cejka, G. Centi, J. Perez-Pariente, W. J. Roth, Catal. Today, 2012, 179, 2.

4 V. Valtchev, G. Majano, S. Mintova, J. Pérez-Ramírez, Chem. Soc. Rev., 2013, 42, 263.

5 M. Hartmann, Angew. Chem. Int. Ed., 2004, 43, 5880.

6 C. H. Christensen, K. Johannsen, E. Törnqvist, I. Schmidt, H. Topsøe, C. H. Christensen, Catal. Today, 2007, 128, 117.

7 K. Egeblad, C. H. Christensen, M. Kustova, C. H. Christensen, Chem. Mater., 2008, 20, 946.

8 M. E. Davis, C. Saldarriaga, C. Montes, J. Garces, C. Crowder Nature, 1988, 331, 698.

9 C. C. Freyhardt, M. Tsapatsis, R. F. Lobo, K. J. Balkus, Jr., M. E. Davis, Nature, 1996, 381, 295.

10 A. Corma, M. J. Diaz-Cabanas, J. L. Jorda, C. Martinez, M. Moliner, Nature, 2006, 443, 842.

11 R. Simancas, D. Dari, N. Velamazán, M.T. Navarro, A. Cantín, J.L. Jordá, G. Sastre, A. Corma, F. Rey, Science, 2010, 26, 1219.

12 L. Tosheva, V. Valtchev, Chem. Mater., 2005, 17, 2494.

13 R. Chal, C. Gerardin, M. Bulut, S. van Donk, Chem. Cat. Chem., 2011, 3, 67.

14 X. Zhang, D. Liu, D. Xu, S. Asahina, K. A. Cychosz, K. V. Agrawal, Y. A. Wahedi, A. Bhan, S. A. Hashimi, O. Terasaki, M. Thommes, M. Tsapatsis, Science, 2012, 336, 1684.

15 W. Chaikittisilp, Y. Suzuki, R. R. Mukti, T. Suzuki, K. Sugita, K. Itabashi, A. Shimojima, T. Okubo, Angew Chem., 2013, 125, 3439.

16 H. Awala. J.-P. Gilson, R. Retoux, P. Boullay, J.-M. Goupil, V. Valtchev, S. Mintova, Nature Mater., 2015, 14, 447.

17 R. Martínez-Franco, C. Paris, M. E. Martínez-Armero, C. Martínez, M. Moliner, A. Corma, Chem. Sci, 2016, DOI: 10.1039/C5SC03019F).

18 A. Corma, V. Fornes, S. B. Pergher, Th. L. M. Maesen, J. G. Buglass, Nature, 1998, 396, 353.

19 S. Maheshwari, E. Jordan, S. Kumar, F. S. Bates, R. L. Penn, D. F. Shantz, M. Tsapatsis, J. Am. Chem. Soc., 2008, 130, 1507.

20 D. P. Serrano, J. M. Escola, P. Pizarro, Chem. Soc. Rev., 2013, 42, 4004.

21 K. Na, G. A. Somorjai, Catal. Lett., 2015, 145, 193.

22 J. Mielby, J. O. Abildstrøm, F. Wang, T. Kasama, C. Weidenthaler, S. Kegnæs, Angew Chem. Int. Ed., 2014, 53, 12513.

23 M. S. Holm, K. Egeblad, P. N. R. Vennestrøm, C. G. Hartmann, M. Kustova, C. H. Christensen, Eur. J. Inorg. Chem., 2008, 5185.

24 P. N. R. Vennestrøm, M. Grill, M. Kustova, K. Egeblad, L. F. Lundegaard, F. Joensen, C. H. Christensen, P. Beato, Catal. Today, 2011, 168, 71.

25 K. Na, M. Choi, R. Ryoo, Micropor. Mesopor. Mater., 2013, $166,3$.

26 J. O. Abildstrøm, M. Kegnæs, G. Hytoft, J. Mielby, S. Kegnæs, Micropor. Mesopor. Mater., 2015, DOI: 10.1016/j.micromeso.2015.12.015

27 C. J. H. Jacobsen, C. Madsen, J. Houzvicka, I. Schmidt, A. Carlsson, J. Am. Chem. Soc., 2000, 122, 7116.

28 M. Yu. Kustova, P. Hasselriis, C. H. Christensen, Catal. Lett., 2004, 96, 205.

29 M. Kustova, K. Egeblad, K. Zhu, C. H. Christensen, Chem. Mater., 2007, 19, 2915. 
30 K. Egeblad, M. Kustova, S. K. Klitgaard, K. Zhu, C. H. Christensen, Micropor. Mesopor. Mater., 2007, 101, 214.

31 A. K. Rovik, S. K. Klitgaard, S. Dahl, C. H. Christensen, I. Chorkendorff, Appl. Catal. A, 2009, 358, 269.

32 S. Takenaka, S. Kobayashi, H. Ogihara, K. Otsuka, J. Catal. , 2003, 217, 79

33 M. Yu. Kustova, A. L. Kustov, C. H. Christensen, Stud. Surf. Sci. Catal., 2005, 158, 255.

34 C. H. Christensen, K. Zhu, M. Kegnæs, K. Egeblad, US Patent 7824657, 2010.

35 C.N. Satterfield, Heterogeneous Catalysis in Industrial Practice, 2nd ed., McGraw-Hill, New York, 1991, 132.

36 I. Schmidt, C. Madsen, C.J.H. Jacobsen, Inorg. Chem., 2000, 39, 2279. 